\title{
Australian Stock Indexes and the Four-Factor Model
}

\section{By Bruce A. Costa, Keith Jakob, Scott J. Niblock \& Elisabeth Sinnewe}

Bruce A. Costa is Professor of Finance, School of Business Administration, University of Montana, United States

Keith Jakob is Donald and Carol Jean Byrnes Professor of Finance, School of Business Administration, University of Montana, United States

Scott J. Niblock is Lecturer of Finance, Southern Cross Business School, Southern Cross University, Australia Elisabeth Sinnewe is Associate Lecturer of Finance, Southern Cross Business School, Southern Cross University, Australia

Stock indexes are passive 'value-weighted' portfolios and should not have alphas which are significantly different from zero. If an index produces an insignificant alpha, then significant alphas for equity funds using this index can be attributed solely to manager performance. However, recent literature suggests that US stock indexes can demonstrate significant alphas, which ultimately raise questions regarding equity fund manager performance in both the US and abroad. In this paper, we employ the Carhart four-factor model and newly available Asian-Pacific risk factors to generate alphas and risk factor loadings for eight Australian stock indexes from January 2004 to December 2012. We find that the initial full sample period analysis does not provide indication of significant alphas in the indexes examined. However, by carrying out 36-month rolling regressions, we discover at least four significant alphas in seven of the eight indexes and factor loading variability. As previously reported in the US, this paper confirms similar issues with the four-factor model using Australian stock indexes and performance benchmarking. In effectively measuring Australian equity fund manager performance, it is therefore essential to evaluate a fund's alpha and risk factors relative to the alpha and risk factors of the appropriate benchmark index.

Keywords: Australia, Carhart, Equity, Funds, Stock Indexes, Performance

\section{Introduction}

The nominal performance of equity fund returns is easy to measure. For instance, nominal returns are simply calculated and compared to the nominal returns of a benchmark index, as specified by the equity fund manager. However, this cursory comparison of nominal performance does not control for differences in risk and style characteristics (e.g., small versus large-cap, value versus growth, etc.) of the fund'. Given the difficulty of accounting for such characteristics, both practitioners and academics have struggled with accurately measuring risk-adjusted performance of equity funds over time. To evaluate the risk-adjusted performance of active equity

funds, it is necessary for the fund manager to employ appropriate passive benchmark indexes (Carhart, 1997; Fama and French, 1993; Gruber, 1996; Jensen, 1968; Roll, 1977; Sharpe, 1966). For example, a benchmark index should be designated by the equity fund manager on the grounds that it is: (1) clearly specified alongside the fund's objectives in the product disclosure statement/prospectus; and (2) commensurate with the fund's investment style and risk characteristics. If an incorrect benchmark index is chosen by the equity fund manager this may inevitably lead to risk-adjusted return underperformance and poor investment decisions being made (Anderson, 2009). 
A benchmark index is deemed to be 'misspecified' if it cannot align itself with the style characteristics of the equity fund it is attempting to benchmark performance against. For instance, it would not be appropriate to evaluate the performance of an equity fund that is heavily weighted with small-cap growth stocks against a benchmark index that consisted mainly of large-cap value stocks. Therefore, an appropriate benchmark index will be one that can evaluate performance and managerial skill by closely tracking the investment style of the equity fund, and not one that can be easily beaten due to misrepresentation of the stocks that actually comprise the fund. If an equity fund is indexing an alternative benchmark then it is essentially passively managed and should be scrutinized for receiving active management fees.

Despite the plethora of equity fund performance research, only a handful of studies have considered benchmark index appropriateness. Brown, Davies and Draper (1992), Grinblatt and Titman (1989, 1994) and Daniel, Grinblatt, Titman and Wermers (1997) briefly discuss the benchmarks chosen by equity fund managers, however, it was not until Tierney and Bailey (1995) that benchmark index selection was deemed important in the context of equity fund performance evaluation. Frost's (2004) study adds to this research by claiming that if equity fund managers do not report their portfolio holdings on a regular basis and benchmark index selection is not scrutinized by market regulators, managers will simply choose indexes that are biased towards overstating the return performance of their funds. Under such settings, managers may benchmark fund returns against popular indexes or indexes that they have performed well against historically; thereby, misrepresenting the fund's investment objectives, style, risk characteristics and/or performance.

Elton, Gruber and Blake (2003) suggest that despite the myriad of available US style indexes, US equity funds managers appear to self-designate benchmark indexes that are misaligned from their investment styles. Costa and Jakob (2006) use data from US stock market indexes to examine whether the alpha and factor loadings generated by Carhart's (1997) four-factor model are sufficient metrics for evaluating equity mutual fund manager risk-adjusted performance. Their findings suggest that the four-factor model is not sufficient as a stand-alone metric of US equity mutual fund performance. This indicates that for US equity funds, manager performance attributed to a significant alpha during a specific period must be adjusted relative to the alpha of the benchmark index over the same period. Similarly, Cremers, Petajisto and Zitzewitz (2012) show that large passive benchmark indexes (such as the S\&P 500 and Russell 1000) are commonly employed by US equity funds managers, and can demonstrate large alphas and exposure to systematic risk factors. Sensoy (2009) further argues the importance of using appropriate benchmark indexes, claiming that they should be aligned directly with the fund's investment style. For instance, Sensoy discovers that a third of US equity fund managers choose benchmark indexes that are not consistent with style characteristics of their funds.

Studies that address this benchmarking issue in Australia are non-existent. To the authors' knowledge, no study explores whether Australian funds are selecting the correct proxy or 'benchmark' index on the basis of well-known risk factors. Given the importance of selecting appropriate benchmark indexes and absence of studies that examine the risk-adjusted metrics of such indexes in Australian equity markets, an opportunity to make a contribution to the fund performance literature exists. Using Costa and Jakob's (2006) methodology, this paper aims to address this gap by examining the efficacy of a multifactor risk adjustment model using Asian-Pacific risk factors and Australian benchmark indexes from 2004 to 2012. Section 2 describes our data and methodology, Section 3 discusses our results and Section 4 summarizes our conclusions.

\section{Data and Methodology}

To obviate the need for currency translation, we use monthly total return data for eight Australian stock market indexes from January 2004 through December 2012 (see Table 1). Data are obtained from SIRCA. To carry out the empirical analysis, we also employ monthly Asian-Pacific risk factors. The risk factors are based on stock return data from Australia, Hong Kong, Singapore and New Zealand and are obtained directly from Kenneth French's website? To measure risk-adjusted return performance of the indexes we use the Carhart (1997) four-factor regression method. The four-factor model applies Fama and French's (1993) three-factor model with an additional factor to capture Jegadeesh and Titman's (1993) one-year momentum anomaly. This regression generates an alpha, similar to the alpha in Jensen (1968), and is designed to capture the riskadjusted return performance of a fund/portfolio. 
Table 1: Australian stock indexes by market capitalization

\begin{tabular}{|l|l|l|l|l|}
\hline Index Source & Index Name & Descriptor & Start Month & End Month \\
\hline S\&P & ASX 20 & ASX20 & JAN 2004 & DEC 2012 \\
\hline S\&P & ASX 50 & ASX50 & JAN 2004 & DEC 2012 \\
\hline S\&P & ASX Midcap 50 & ASXMC50 & JAN 2004 & DEC 2012 \\
\hline S\&P & ASX 100 & ASX100 & JAN 2004 & DEC 2012 \\
\hline S\&P & ASX 200 & ASX200 & JAN 2004 & DEC 2012 \\
\hline S\&P & ASX Small Ordinaries & ASXSO & JAN 2004 & DEC 2012 \\
\hline S\&P & ASX 300 & ASX300 & JAN 2004 & DEC 2012 \\
\hline S\&P & All Ordinaries & ASXAO & JAN 2004 & DEC 2012 \\
\hline
\end{tabular}

To test whether Australian stock indexes have statistically significant alphas and factor loadings we follow the approach taken by Costa and Jakob (2006). For our initial analysis we use the following four-factor model:

$$
r_{i}=\alpha_{i}+\beta_{1 i} R M R F_{t}+\beta_{2 i} S M B_{t}+\beta_{3 i} H M L_{t}+\beta_{4 i} W M L_{t}+\varepsilon_{i}
$$

where $r i$ is the monthly index return minus the US onemonth Treasury bill return ${ }^{3}, R M R F$ is the value-weighted Asian-Pacific market portfolio minus the US one-month Treasury bill return and $S M B, H M L$ and $W M L$ are returns on Asian-Pacific value-weighted zero-investment, factormimicking portfolios for size, book-to-market equity, and lagged momentum in stock returns, respectively ${ }^{4}$. It should be noted that to perform the asset pricing tests, we use local Asian-Pacific factors instead of US factors. Griffin (2002) argues that local factors outperform global factors in explaining stock returns based on a sample of UK, Japanese and Canadian returns.

From the regression outputs the factor loadings on RMRF, $S M B$, and HML should be related to the orientation of the particular index. Most broad based indexes hold a fairly large portion of the entire market; therefore we expect the factor loadings on RMRF to be positive and significant. For an index with smaller (larger) capitalization stocks we expect a positive (negative) SMB factor loading. For growth stock indexes (value stock indexes) we would expect a negative (positive) HML factor loading. It is anticipated that unmanaged indexes do not follow any particular momentum strategy, therefore WML factor loadings for Jegadeesh and Titman's (1993) momentum factor should be statistically insignificant.

To gain a better understanding of how alpha and the factor loadings change through time we break the full 108-month sample period into rolling 36-month periods. MorningStar generally reports mutual fund returns over one-, three-, five-, and ten-year periods. However, the most popular time horizon is the 36-month rolling average horizon. To remain consistent with industry reporting periods we construct 36-month sub-periods for all indexes under investigation. Specifically, we roll both the beginning and ending months forward by one month to February 2004 and January 2007, respectively. We continue to roll forward in one month increments to create subsequent sub-samples until we reach the ending month of December 2012. With this 'rolling average' approach we create 73 thirty-six month sub-periods from the total 108-month period. We use the four-factor model and run regressions for all 73 subsamples.

The testable hypotheses for this study are:

H1 Australian stock market indexes do not generate alphas which are significantly different from zero.

H2 Australian stock market indexes generate RMRF factor loadings which are positive and significantly different from zero.

H3 Larger capitalized Australian stock market indexes generate negative $S M B$ factor loadings which are significantly different from zero.

H4 Smaller capitalized Australian stock market indexes generate positive $S M B$ factor loadings which are significantly different from zero.

H5 Growth orientated Australian stock market indexes generate negative HML factor loadings which are significantly different from zero.

H6 Value orientated Australian stock market indexes generate positive HML factor loadings which are significantly different from zero.

H7 Australian stock market indexes do not generate WML factor loadings which are significantly different from zero. 


\section{Results}

Table 2 shows the four-factor regression results for the full sample period. All eight regressions have significant explanatory power, with adjusted $R^{2}$ ranging from 0.637 to 0.779. Interestingly, the Asian-Pacific model works best for the ASXSO with an adjusted $R^{2}$ of 0.779 and provides strongest estimates on RMRF, SMB and HML. This seems to suggest that the model works best for small firms, which may be due to the relevance of small stocks on the other stock exchanges included in the calculation of the factor loadings (i.e., Hong Kong, Singapore and New Zealand). Over the full sample period none of the eight indexes generate statistically significant alphas, so Hypothesis 1 is accepted. We find RMRF factor loadings to be positive and statistically significant, but the magnitudes of the coefficients are smaller than those documented in the regressions of US indexes. For instance, Costa and Jakob (2006) found that the vast majority of US indexes have RMRF factor loadings that were close to one. Nevertheless, our Australian index results suggest factor loadings that range between 0.48 and 0.69 are consistent with the level of market risk associated with the typical Asian-Pacific benchmark, so Hypothesis 2 is accepted.

\section{Table 2: Risk-adjusted performance of Australian stock indexes}

\begin{tabular}{|c|c|c|c|c|c|c|c|}
\hline Descriptor & Sample & Adj. $R^{2}$ & Intercept & RMRF & SMB & $\mathrm{HML}$ & WML \\
\hline ASX2O & 108 & 0.672 & $\begin{array}{r}0.0014 \\
(0.63)\end{array}$ & $\begin{array}{r}0.4774 \\
(13.50)^{* * *}\end{array}$ & $\begin{array}{r}-0.3623 \\
(-4.47)^{* * *}\end{array}$ & $\begin{array}{r}-0.2989 \\
(-3.35)^{* * *}\end{array}$ & $\begin{array}{l}0.0933 \\
(1.67)^{*}\end{array}$ \\
\hline ASX50 & 108 & 0.708 & $\begin{array}{r}0.0007 \\
(0.35)\end{array}$ & $\begin{array}{r}0.4908 \\
(14.79)^{* * *}\end{array}$ & $\begin{array}{r}-0.3016 \\
(-3.96)^{* * *}\end{array}$ & $\begin{array}{r}-0.2708 \\
(-3.24)^{* * *}\end{array}$ & $\begin{array}{r}0.0857 \\
(1.63)\end{array}$ \\
\hline ASXMC50 & 108 & 0.668 & $\begin{array}{r}-0.0004 \\
(-0.14)\end{array}$ & $\begin{array}{r}0.5940 \\
(13.22)^{* * *}\end{array}$ & $\begin{array}{l}-0.0816 \\
(-0.79)\end{array}$ & $\begin{array}{c}-0.2423 \\
(-2.14)^{* *}\end{array}$ & $\begin{array}{r}0.0192 \\
(0.27)\end{array}$ \\
\hline ASX100 & 108 & 0.637 & $\begin{array}{r}0.0017 \\
(0.62)\end{array}$ & $\begin{array}{r}0.5012 \\
(11.84)^{* * *}\end{array}$ & $\begin{array}{r}-0.0721 \\
(-0.74)\end{array}$ & $\begin{array}{r}-0.3554 \\
(-3.33)^{* * *}\end{array}$ & $\begin{array}{r}0.0575 \\
(0.86)\end{array}$ \\
\hline ASX200 & 108 & 0.732 & $\begin{array}{r}0.0004 \\
(0.20)\end{array}$ & $\begin{array}{r}0.5155 \\
(15.66)^{* * *}\end{array}$ & $\begin{array}{c}-0.2371 \\
(-3.14)^{* * *}\end{array}$ & $\begin{array}{r}-0.2630 \\
(-3.17)^{* * *}\end{array}$ & $\begin{array}{r}0.0774 \\
(1.49)\end{array}$ \\
\hline ASXSO & 108 & 0.779 & $\begin{array}{r}-0.0011 \\
(-0.40)\end{array}$ & $\begin{array}{r}0.6879 \\
(16.13)^{* * *}\end{array}$ & $\begin{array}{r}0.2371 \\
(2.42)^{* *}\end{array}$ & $\begin{array}{r}-0.2937 \\
(-2.73)^{* * *}\end{array}$ & $\begin{array}{r}-0.0137 \\
(-0.20)\end{array}$ \\
\hline ASX300 & 108 & 0.738 & $\begin{array}{r}0.0003 \\
(0.17)\end{array}$ & $\begin{array}{r}0.5199 \\
(15.84)^{* * *}\end{array}$ & $\begin{array}{r}-0.2209 \\
(-2.93)^{* * *}\end{array}$ & $\begin{array}{r}-0.2680 \\
(-3.24)^{* * *}\end{array}$ & $\begin{array}{r}0.0778 \\
(1.50)\end{array}$ \\
\hline ASXAO & 108 & 0.751 & $\begin{array}{r}0.0004 \\
(0.20)\end{array}$ & $\begin{array}{r}0.5272 \\
(16.19)^{* * *}\end{array}$ & $\begin{array}{r}-0.1646 \\
(-2.20)^{* *}\end{array}$ & $\begin{array}{r}-0.2775 \\
(-3.38)^{* * *}\end{array}$ & $\begin{array}{r}0.0773 \\
(1.50)\end{array}$ \\
\hline
\end{tabular}

Notes: Monthly excess, risk-adjusted returns, based on the four-factor model for eight Australian stock market capitalization indexes for the time period available (i.e., January 2004 to December 2012) (see Model 1). * Significant at the .10 level. ** Significant at the .05 level. *** Significant at the .01 level.

The SMB factor loadings for the stock indexes are both negative and statistically significant ${ }^{5}$ (with the exception of ASXMC50 and ASX100, which are negative but not significant5, and ASXSO, which is positive and significant). This suggests that seven of the eight Australian indexes are more mid to large cap orientated relative to the AsianPacific market factor portfolio. The SMB factor loading for
ASXSO is of no surprise given the small cap composition of the index. Therefore, both Hypothesis 3 and 4 are accepted. The HML factor loading for all eight indexes are both negative and statistically significant. This suggests that the Australian stock market is more growth oriented relative to the Asian-Pacific market factor portfolio, so Hypothesis 5 is accepted and Hypothesis 6 is rejected. 
The WML factor loadings are mainly positive and statistically insignificant (with the exception of ASX20 and ASXSO). ASX20 has a positive and significant factor loading for Jegadeesh and Titman's (1993) momentum factor at the ten percent level, while ASXSO has a negative coefficient but is not significant. These results suggest that momentum does not play much of a role in the Australian stock market, which is consistent with the notion that unmanaged indexes should not have significant momentum factor loadings. Therefore, Hypothesis 7 is accepted for seven of the eight indexes.
We also generate rolling 36-month sample periods starting with the period between January 2004 and December 2006. Table 3 highlights summary statistics for the 36-month rolling regressions of the stock indexes. All of the indexes, with the exception of ASX20, have at least four statistically significant 36-month alphas. Hypothesis 1 is therefore rejected under these testing conditions. For all indexes the range of alphas includes both positive and negative values. All indexes exhibit a similar trend, starting out positive and declining over the sample period.

\section{Table 3: Summary of 36-month rolling regressions of Australian stock indexes}

\begin{tabular}{|c|c|c|c|c|c|c|}
\hline Descriptor & Stats & Alpha & RMRF & SMB & $\mathrm{HML}$ & WML \\
\hline \multirow[t]{4}{*}{ ASX20 } & Max & 0.007077 & 0.702456 & -0.13767 & 0.120506 & 0.285449 \\
\hline & Min & -0.00631 & 0.440453 & -0.67957 & -0.53144 & -0.1235 \\
\hline & Range & 0.013382 & 0.262003 & 0.541897 & 0.651951 & 0.408951 \\
\hline & Sig. Obs. & 0 & 73 & 58 & 37 & 2 \\
\hline \multirow[t]{4}{*}{ ASX50 } & Max & 0.00739 & 0.699296 & -0.13949 & 0.132778 & 0.190736 \\
\hline & Min & -0.00696 & 0.453309 & -0.59408 & -0.48055 & -0.12928 \\
\hline & Range & 0.014352 & 0.245987 & 0.454592 & 0.613327 & 0.320016 \\
\hline & Sig. Obs. & 4 pos. & 73 & 55 & 36 & 0 \\
\hline \multirow[t]{4}{*}{ ASXMC50 } & Max & 0.013006 & 0.702752 & 0.157392 & 0.003977 & 0.267157 \\
\hline & Min & -0.01097 & 0.32505 & -0.48228 & -0.42014 & -0.30595 \\
\hline & Range & 0.023977 & 0.377702 & 0.639671 & 0.424114 & 0.57311 \\
\hline & Sig. Obs. & 6 pos. / 5 neg. & 73 & 14 & 11 & 0 \\
\hline \multirow[t]{4}{*}{ ASX100 } & Max & 0.011093 & 0.79 & 0.213561 & 0.183424 & 0.173194 \\
\hline & Min & -0.0051 & 0.408813 & -0.2447 & -0.59046 & -0.32989 \\
\hline & Range & 0.016197 & 0.381188 & 0.458258 & 0.773879 & 0.503084 \\
\hline & Sig. Obs. & 4 pos. & 73 & 0 & 43 & 0 \\
\hline \multirow[t]{4}{*}{ ASX200 } & Max & 0.008416 & 0.700137 & -0.06444 & 0.123401 & 0.144298 \\
\hline & Min & -0.00704 & 0.436525 & -0.552 & -0.46172 & -0.12807 \\
\hline & Range & 0.015452 & 0.263612 & 0.48756 & 0.585119 & 0.272372 \\
\hline & Sig. Obs. & 4 pos. & 73 & 41 & 34 & 0 \\
\hline \multirow[t]{4}{*}{ ASXSO } & Max & 0.010095 & 0.837484 & 0.502034 & 0.152962 & 0.310629 \\
\hline & Min & -0.01052 & 0.339487 & -0.30159 & -0.45185 & -0.17555 \\
\hline & Range & 0.020614 & 0.497997 & 0.803621 & 0.604811 & 0.486182 \\
\hline & Sig. Obs. & 4 pos. / 3 neg. & 73 & 15 & 22 & 0 \\
\hline \multirow[t]{4}{*}{ ASX300 } & Max & 0.008343 & 0.707691 & -0.04515 & 0.116643 & 0.141313 \\
\hline & Min & -0.00711 & 0.443417 & -0.54019 & -0.46658 & -0.13493 \\
\hline & Range & 0.015456 & 0.264275 & 0.495038 & 0.583225 & 0.276239 \\
\hline & Sig. Obs. & 4 pos. & 73 & 38 & 35 & 0 \\
\hline \multirow[t]{4}{*}{ ASXAO } & Max & 0.00838 & 0.694154 & -0.00188 & 0.111875 & 0.148637 \\
\hline & Min & -0.00658 & 0.426761 & -0.47369 & -0.46698 & -0.10909 \\
\hline & Range & 0.014958 & 0.267394 & 0.471801 & 0.578852 & 0.25773 \\
\hline & Sig. Obs. & 4 pos. & 73 & 30 & 35 & 0 \\
\hline
\end{tabular}

Notes: 36-month rolling regressions starting with the period January 2004 - December 2006 and ending with the period January 2010 - December 2012. The significant observations are reported at the ten percent or better level.
As an illustrative example, Figures 1 - 8 present the results for the Australian stock indexes in graphical format. The graphs clearly demonstrate how alpha varies over time. For instance, the ASX50MC has six 36-month periods where 
Australian Stock Indexes and the Four-Factor Model

the alpha for the index is positive and significant, and five 36-month periods where the alpha for the index is negative and significant. The results from the rolling 36-month regressions show that four-factor alpha measurement for mutual funds must be adjusted for the magnitude of the alpha of the underlying benchmark.

Figure 1: Example plots of 36-month alphas from January 2004 through December 2012 for ASX20.

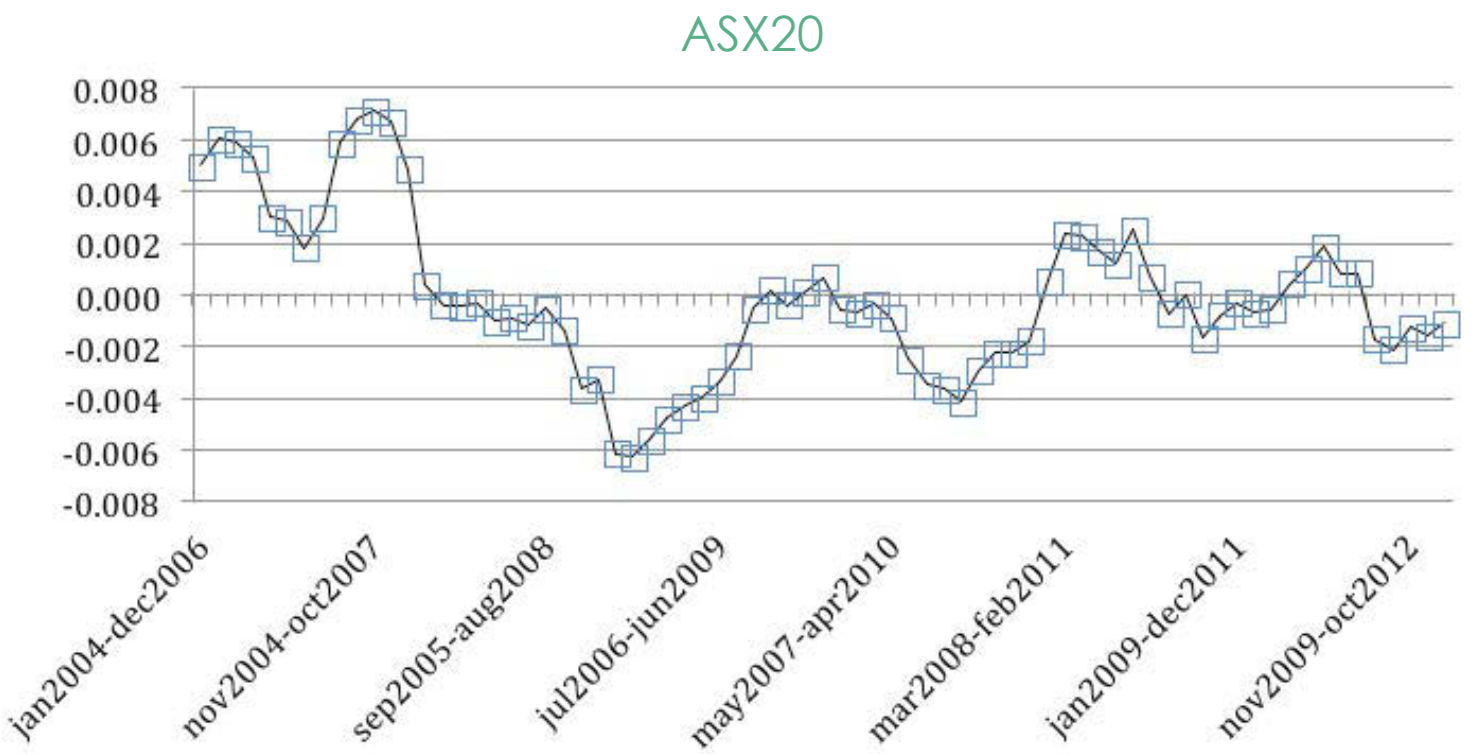

Notes: 36-month rolling regressions starting with the period January 2004 - December 2006 and ending with the period January 2010 - December 2012.

Significant at the $10 \%$ level or better. $\square$ Not significant.

Figure 2: Example plots of 36-month alphas from January 2004 through December 2012 for ASX50.

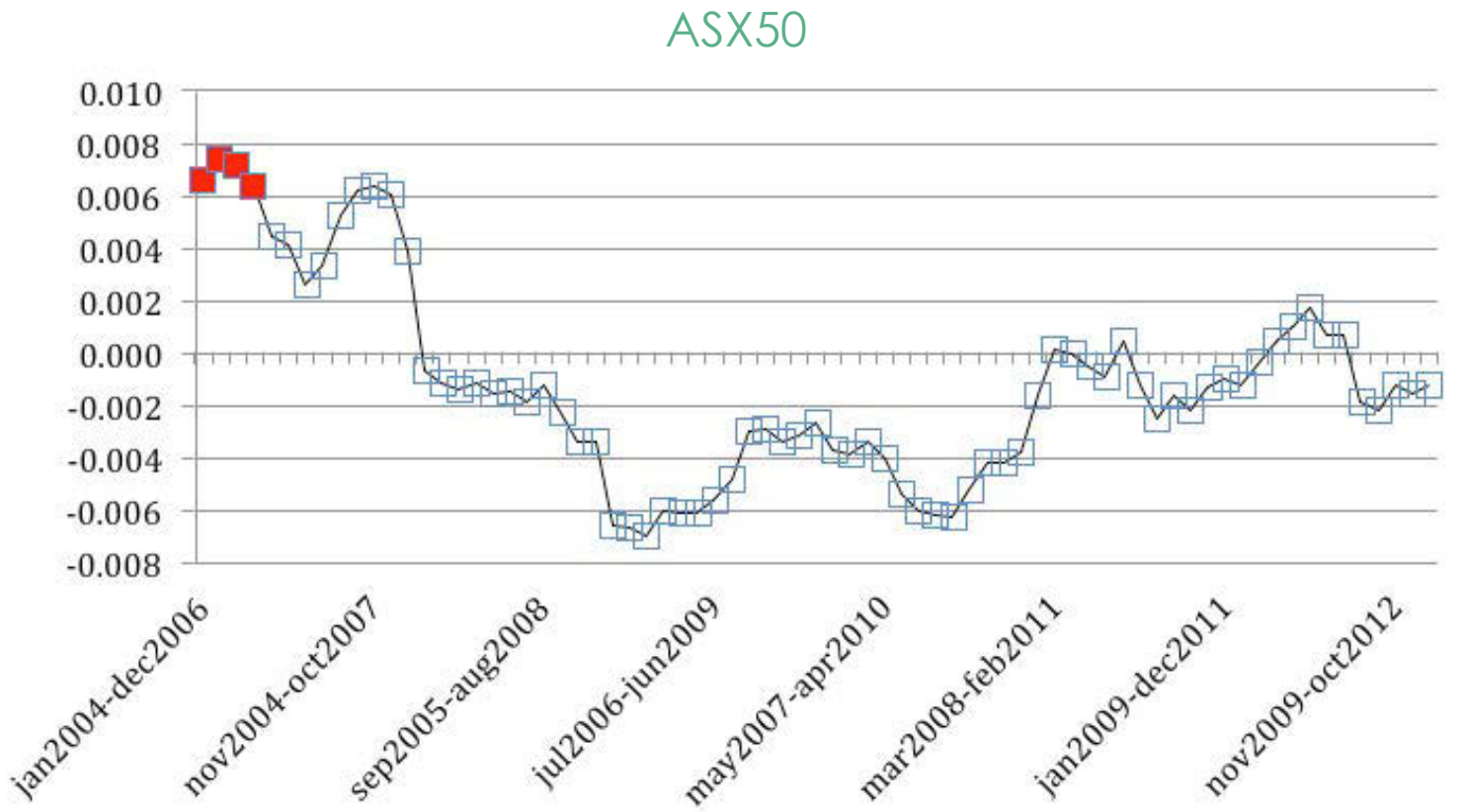

Notes: 36-month rolling regressions starting with the period January 2004 - December 2006 and ending with the period January 2010 - December 2012.

- Significant at the $10 \%$ level or better. $\square$ Not significant. 
Figure 3: Example plots of 36-month alphas from January 2004 through December 2012 for ASXMC50.

\section{ASX50MC}

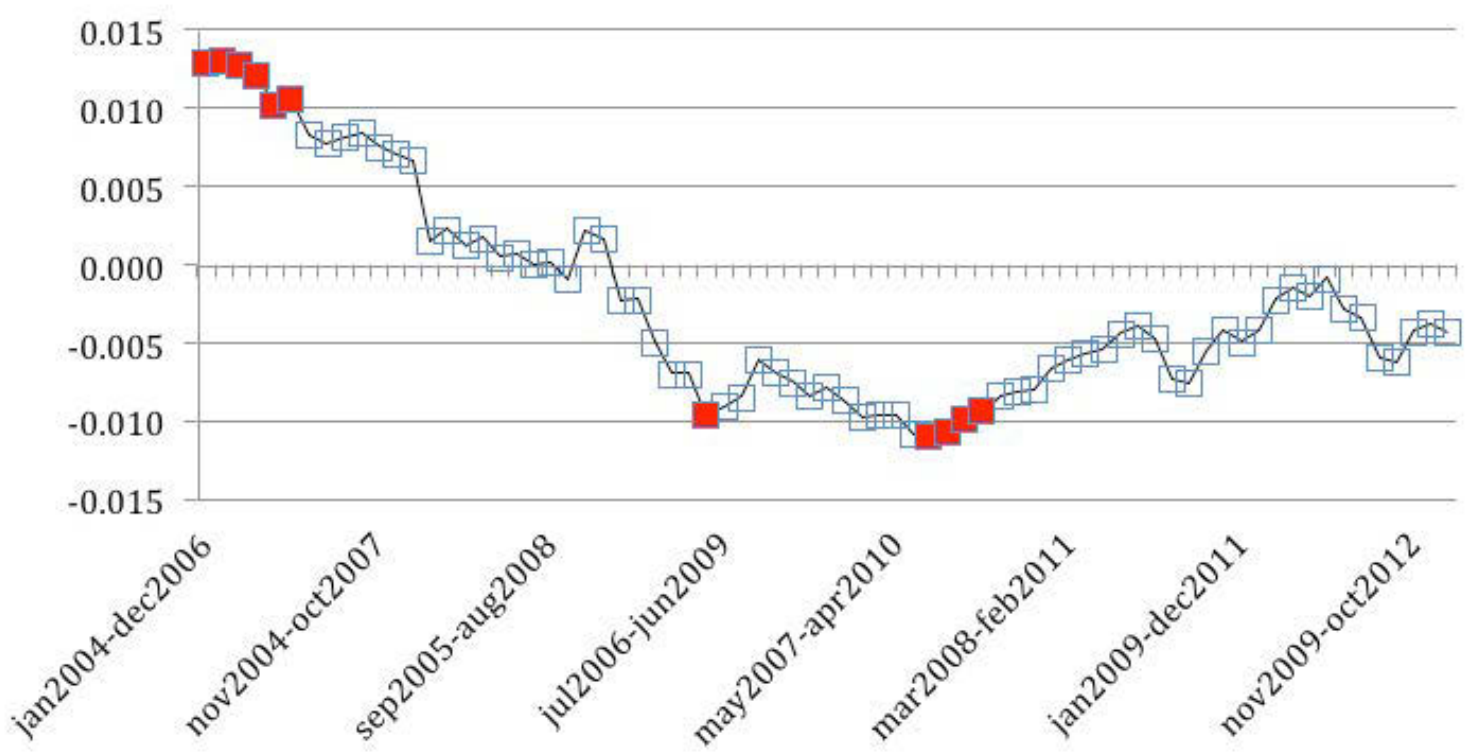

Notes: 36-month rolling regressions starting with the period January 2004 - December 2006 and ending with the period January 2010 - December 2012.

Significant at the $10 \%$ level or better. $\square$ Not significant.

Figure 4: Example plots of 36-month alphas from January 2004 through December 2012 for ASX100.

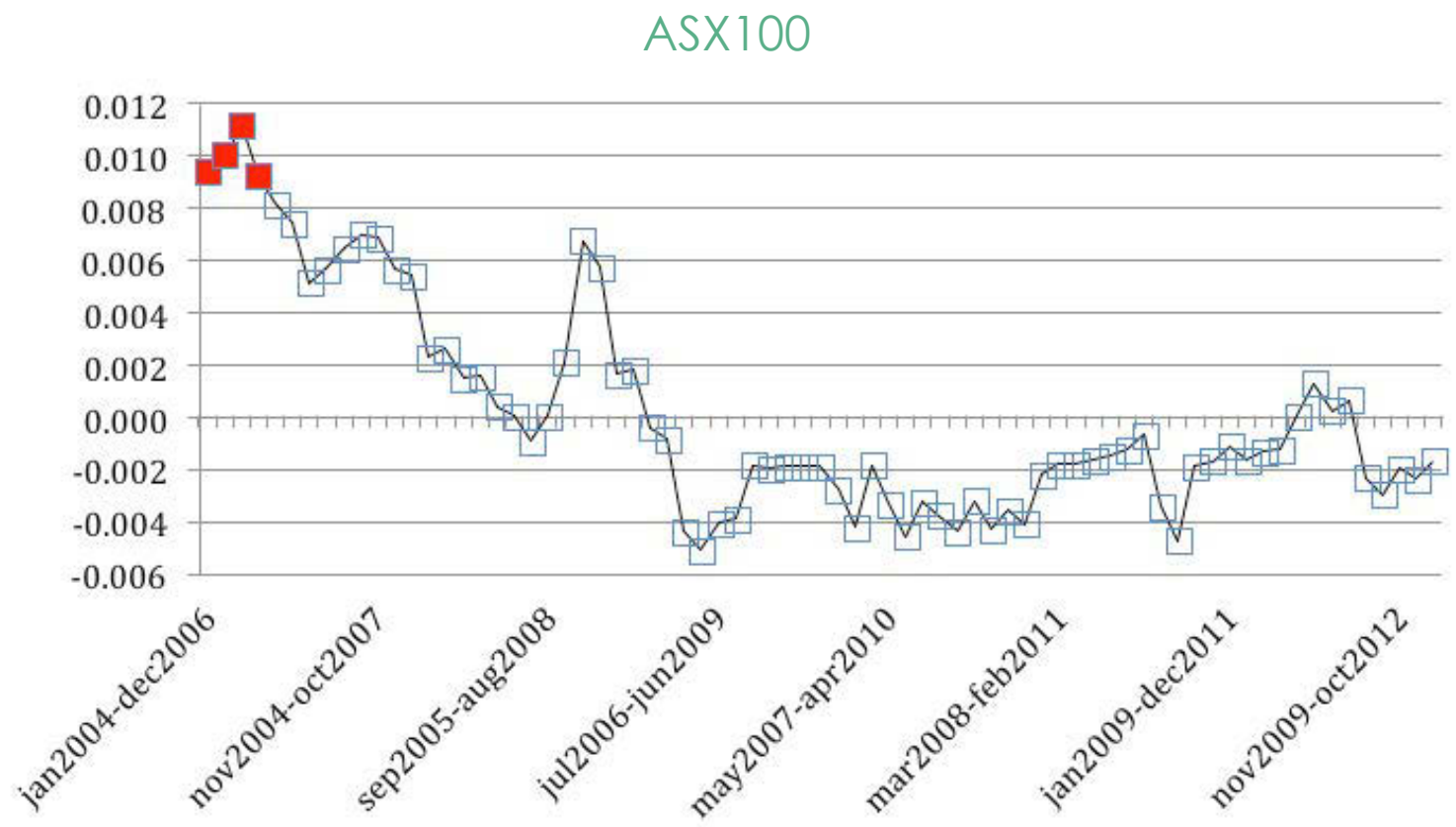

Notes: 36-month rolling regressions starting with the period January 2004 - December 2006 and ending with the period January 2010 - December 2012.

Significant at the $10 \%$ level or better. $\square$ Not significant. 
Australian Stock Indexes and the

Four-Factor Model

Figure 5: Example plots of 36-month alphas from January 2004 through December 2012 for ASX200.

\section{ASX200}

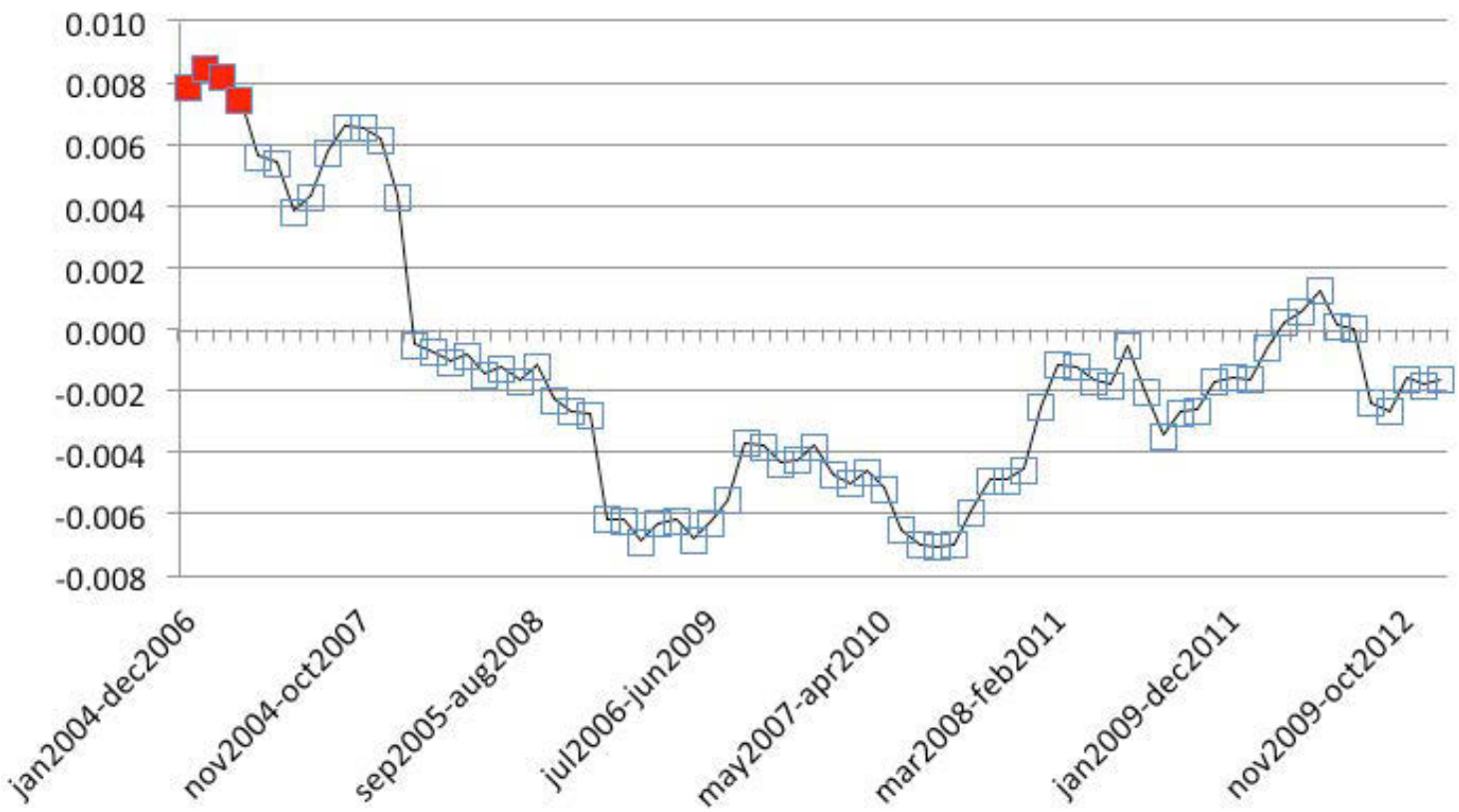

Notes: 36-month rolling regressions starting with the period January 2004 - December 2006 and ending with the period January 2010 - December 2012.

Significant at the $10 \%$ level or better. $\square$ Not significant.

Figure 6: Example plots of 36-month alphas from January 2004 through December 2012 for ASXSO.

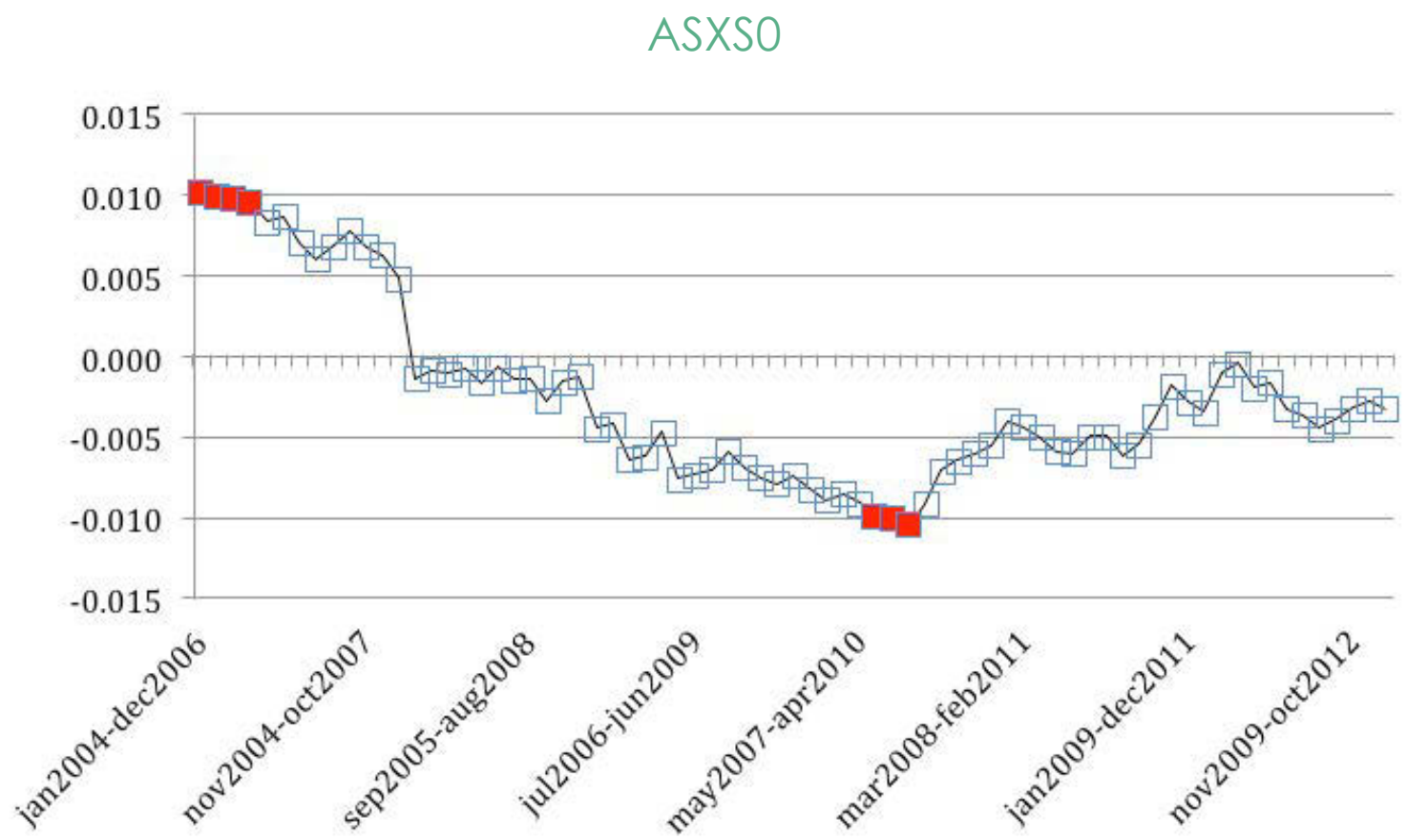

Notes: 36-month rolling regressions starting with the period January 2004 - December 2006 and ending with the period January 2010 - December 2012.

- Significant at the $10 \%$ level or better. $\square$ Not significant. 
Figure 7: Example plots of 36-month alphas from January 2004 through December 2012 for ASX300.

\section{ASX300}

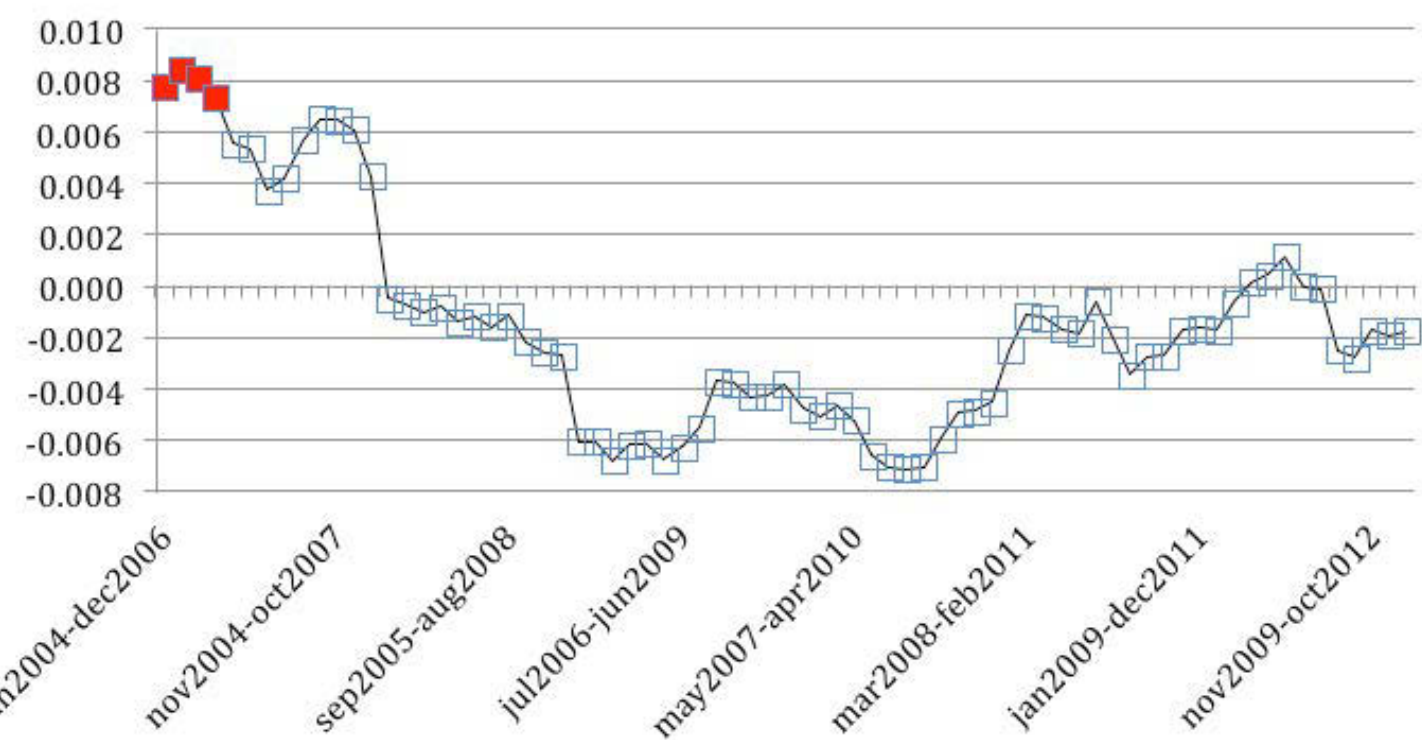

Notes: 36-month rolling regressions starting with the period January 2004 - December 2006 and ending with the period January 2010 - December 2012.

Significant at the $10 \%$ level or better. $\square$ Not significant.

Figure 8: Example plots of 36-month alphas from January 2004 through December 2012 for ASXAO.

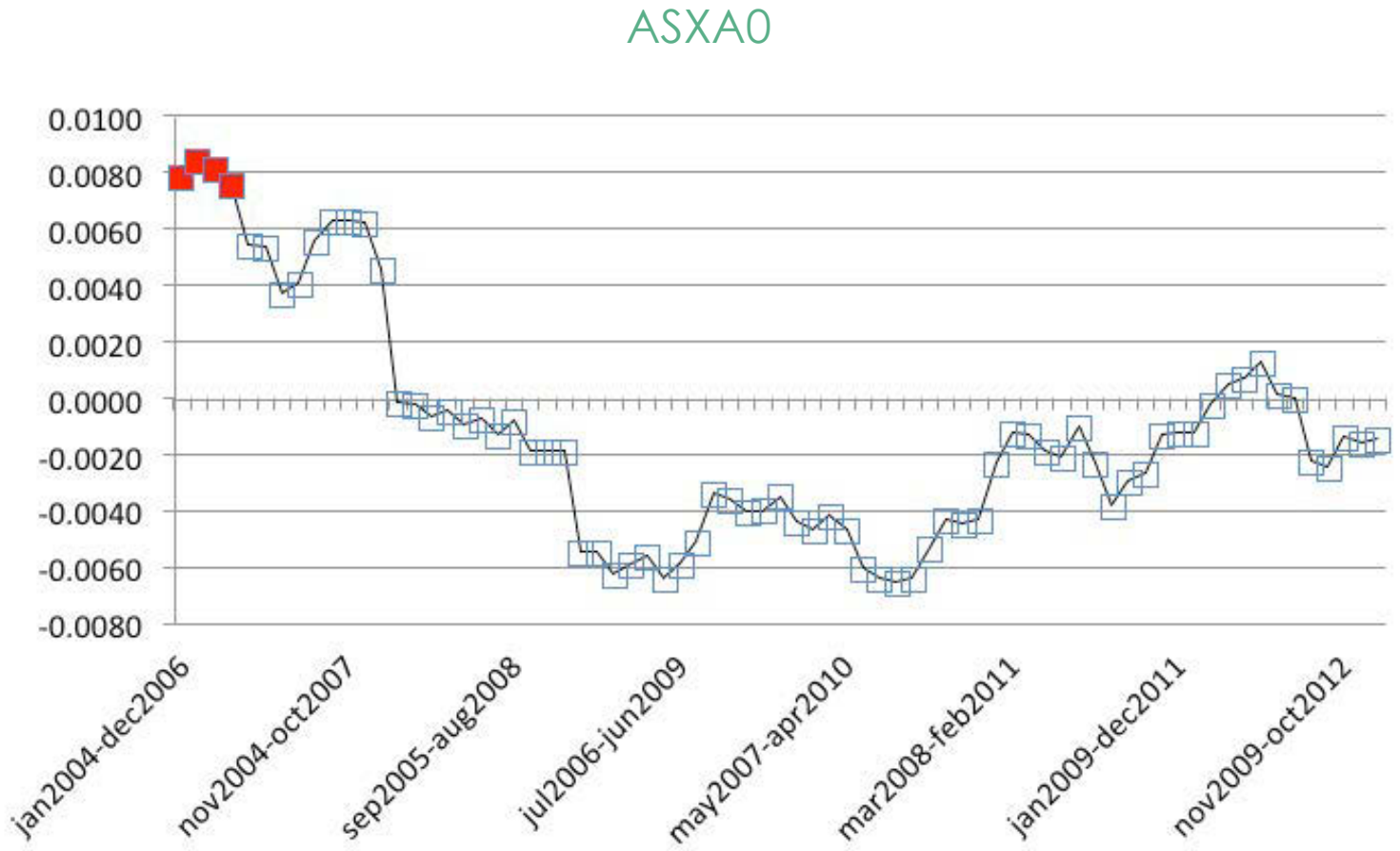

Notes: 36-month rolling regressions starting with the period January 2004 - December 2006 and ending with the period January 2010 - December 2012.

Significant at the $10 \%$ level or better. $\square$ Not significant. 
Table 3 also presents summary data on the four risk factor loadings. The significant observations and ranges in values vary dramatically across the four factors over time. However, RMRF, SMB and HML findings are consistent with the previous full period Hypothesis testing (as indicated by acceptance of Hypotheses 2-6). Notably, all of the indexes (with the exception of ASX20 and only 2 observations reported) do not have significant WML factor loadings, which again accepts Hypothesis 7 and further confirms the lack of momentum in the Australian stock market.

In untabulated results we check the robustness of our findings by re-running model (1) on both the entire sampling period and rolling regressions over 36-month windows using the four-factor model based on Australian factor data. We construct the Australian RMRF, SMB, HML and WML factors following as closely as possible the approach outlined in Fama and French (2012). The findings of the robustness tests are supportive of our main findings using Asian-Pacific factor loadings. While we find no significant alphas for the entire sampling period, the observations of significant alphas in the rolling regressions ranges from 0 (ASX20) to 24 (ASXAO), again clearly rejecting Hypothesis 1. However, differences between the Asian-Pacific model and the Australian model become evident when studying the factor loadings. For example, RMRF is much closer to 1 , as documented in the US (Costa and Jakob, 2006). Contrary to the Asian- Pacific results, five out of the eight examined indexes load significantly positive on HML which suggests that the Australian indexes are tilted towards value firms rather than growth firms. However, findings on SMB and WML remain virtually unchanged.

Overall, the findings suggest that significant alphas for Australian indexes are observed when employing 36-month rolling regressions. It is also evident that the factor loadings for all four risk characteristics can change sign and magnitude over time. Moreover, caution must be taken when interpreting alphas of Australian equity funds, particularly if fund managers specify any of the indexes examined in this study as their performance benchmark. When analyzing fund risk characteristics, it is therefore critical to use the appropriate benchmark index and time period. For instance, using US data, Costa and Jakob (2010) demonstrate a pair-wise F-test between alphas and coefficients of the benchmark and mutual funds to deal with this model misinterpretation. Our results suggest that a similar approach should be employed with Australian stock indexes and mutual funds.

\section{Conclusion}

Interpretation of a significant alpha is generally viewed as abnormal manager performance. While this may be possible for equity funds/portfolios, unmanaged stock indexes should not generate significant alphas. Using Carhart's (1997) four-factor model we generate alphas and risk factor loadings for Australian stock indexes. The initial full sample period analysis does not provide indication of significant alphas in the indexes examined. However, by carrying out 36-month rolling regressions, we discover at least four significant alphas in seven of the eight indexes. As previously reported in the US, this paper confirms that similar issues exist with the four-factor model using Australian indexes. Prior literature (Costa and Jakob, 2006, 2010) using US data has shown that it is essential to evaluate an equity fund's alpha and risk factors relative to the alpha and risk factors of the selected benchmark index. Given the variability in alphas and factor loadings observed, Australian equity fund performance should be evaluated and benchmarked against appropriate indexes over the same time horizons.

\section{Acknowledgements}

This work was supported, in part, by a grant from the School of Business Administration at the University of Montana and the Donald and Carol Jean Byrnes Professorship. We would also like to thank S.G. Long and Company, Prof. Kenneth French, Prof. Terry Walter and SIRCA for their assistance with this paper. 


\section{References}

Anderson, A. (2009), Own the world: how smart investors create global portfolios. John Wiley and Sons.

Brown, G., Davies, D., and Draper, P. (1992), Pension fund trustees and performance measurement. Management Accounting. 7, 38-44.

Carhart, M. (1997), On persistence in mutual fund performance. The Journal of Finance. 52, 57-86.

Costa, B., and Jakob, K.( 2006), Do stock indexes have abnormal performance? The Journal of Performance Measurement, 11 (1), 8-18.

Costa, B., and Jakob, K. (2010), Enhanced performance measurement of mutual funds: running the benchmark index through the hurdles. Journal of Applied Finance. 20(1), 95-102.

Cremers, M., Petajisto, A., and Zitzewitz, E. (2012), Should benchmark indices have alpha? Revisiting performance evaluation. National Bureau of Economic Research.

Daniel, K., Grinblatt, M., Titman, S., and Wermers, R. (1997), Measuring mutual fund performance with characteristic based benchmarks. The Journal of Finance. 52(3), 1035-1058.

Elton, E. J., Gruber, M. J., and Blake, C. R. (2003), Incentive fees and mutual funds. The Journal of Finance. 58(2), 779-804.

Fama, E., and French, K. (1993), Common risk factors in the returns on stocks and bonds. Journal of Financial Economics. 33, 3-55.

Fama, E., and French, K. (2012), Size, value, and momentum in international stock returns. Journal of Financial Economics. 105(3), 457-472.
Frost, S. M. (2004), The bank analyst's handbook: money, risk, and conjuring tricks. John Wiley and Sons Griffin, J.M. (2002), Are the Fama and French factors global or country specific? Review of Financial Studies. 15, 783-803.

Grinblatt, M., and Titman, S. (1989), Mutual fund performance: an analysis of quarterly portfolio holdings. The Journal of Business. 62(3), 393-416.

Grinblatt, M., and Titman, S. (1994), A study of monthly mutual fund returns and performance evaluation techniques. Journal of Financial and Quantitative Analysis. 29, 419-444.

Gruber, M. (1996), Another puzzle: the growth in actively managed mutual funds. The Journal of Finance. $51,783-810$.

Jegadeesh, N., and Titman, S. (1993), Returns to buying winners and selling losers: implications for stock market efficiency. The Journal of Finance. 48, 6591.

Jensen, M. C. (1968), The performance of mutual funds in the period 1945-1964. The Journal of Finance. 23(2), 389-416.

Roll, R. (1977), A critique of the asset pricing theory's tests. Journal of Financial Economics. 4, 129-176.

Sensoy, B. A. (2009), Performance evaluation and self-designated benchmark indexes in the mutual fund industry. Journal of Financial Economics. 92(1), 25-39.

Sharpe (1966), Mutual fund performance. The Journal of Business. 39(1), 119-138.

Tierney, D. E., and Bailey, J. V. (1995), Benchmark orthogonality properties. The Journal of Portfolio Management. 21 (3), 27-31. 


\section{Notes:}

1. Most market regulators require equity fund managers to report their past performance with a comparative benchmark index, but not on a risk-adjusted basis.

2. To ensure that our results are replicable and consistent with Fama and French (2012), we use the Asian-Pacific region risk factors in our main analysis. For more detailed information about the risk factors see:

http://mba.tuck.dartmouth.edu/pages/faculty/ken.french/data_library.html.

3. In analogy with Fama and French (2012), we utilize the US one-month Treasury bill return due to the difficulty in obtaining a singular and comparable measure of a risk-free rate for the Asian-Pacific region. The Asian-Pacific factors are composed of returns from four different countries, therefore an international standard risk-free rate was chosen.

4. To construct the Asian-Pacific factors, Fama and French (2012) form six size/value (SG, SN, SV, BG, BN and BV) and six size/momentum (SL, SN, SW, BL, BN and BW) portfolios, whereas the size split is 90th (=big) and 10th (=small) and the value(momentum) breakpoints are the 30th and 70th percentile. For each of the $2 \times 6$ portfolios they use valueweighted returns. RMRF is also value-weighted. They calculate the equal-weighted average between the portfolios to obtain the SMB, HML and WML factors.

5. The ASX100 comprises ASX50 and ASX50MC firms. It is expected that the presence of midcap firms in the ASX100 offsets the size tilt in the ASX100.

\section{Corresponding Author:}

Scott J. Niblock, Southern Cross Business School, Southern Cross University, Gold Coast Campus, Bilinga, QLD 4225 Australia, Ph: +6175589 3098. Email scott.niblock@scu.edu.au 